Supporting Information

\title{
A Programmable Toolkit to Dynamically Signal Cells Using Peptide Strand Displacement
}

Kyle D. Riker, Margaret L. Daly, Micah J. Papanikolas, Tengyue Jian, Stephen J. Klawa, Jacqueline (Yalin) S. Shin (Sahin), Dingyuan Liu, Anamika Singh, A. Griffin Miller, Ronit Freeman*

Department of Applied Physical Sciences, University of North Carolina, Chapel Hill, NC 27599, USA.

*Email: ronifree@email.unc.edu 


\section{Supplementary Peptide Characterization, Schematics and Experimental Data}

Table S1- Peptide sequences

S1- Peptide_I

S2-Peptide_S

S3- Surface synthesis scheme

S4- Peptide_D

S5- XPS atomic composition

S6- CD of peptide_D and peptide_I + peptide_D

Table S2- Molar ellipticity ratios

S7- CD melting analysis

S8-Peptide_I-biotin

S9- Fluorescent modification on surface

S10-Peptide_D-mis

S11- Testing specificity of the displacement process

S12- Peptide density on the surface

S13- SEM of cells on displayed and displaced surfaces

S14- Peptide_I-RGES

S15- ELISA

S16- Focal adhesion/integrin staining of negative controls

Table S3- Comparison of switchable platforms

S17- Cell area with time of display

S18- Cell on RGDS surfaces at extended time points

S19- Explanation of enrichment ratio calculation

S20- Kinetics of cell spreading on APTES, glass, and RGDS-displayed surfaces

S21-CD kinetics of peptide displacement in solution

S22- Cell number over ON-OFF cycles

S23- Cell viability over ON-OFF cycles

\section{Videos}

S1- Cells spreading on RGDS-displayed surface

S2- Cells on alginate surface

S3-Cells on peptide_S-modified surface

S4- HEK cells on RGDS-displayed surface

S5-Cell spreading and contracting over multiple cycles

S6- Cells on glass

S7- Cells on APTES-coated surface 


\section{Peptide Characterization}

\begin{tabular}{|l|l|}
\hline Peptide name & Peptide sequences \\
\hline peptide_I & $\begin{array}{l}\mathrm{H}- \\
\text { KIAALKEKIAALKEKIAALKEKIAALKEGGGGGRGDS- } \\
\mathrm{NH}_{2}\end{array}$ \\
\hline peptide_S & $\mathrm{H}-$ Kaz-PEG $_{2}$-EIAALEKEIAALEKEIAALEK-NH 2 \\
\hline peptide_D & H-EIAALEKEIAALEKEIAALEKEIAALEK-NH 2 \\
\hline peptide_D-mis & H-KIAALKKKIAALKKKIAALKKKIAALKK-NH 2 \\
\hline peptide_I-RGES & $\begin{array}{l}\text { H-KIAALKEKIAALKEKIAALKEKIAALKEGGGGGRGES- } \\
\text { NH }\end{array}$ \\
\hline peptide_I-Biotin & $\begin{array}{l}\text { H- } \\
\text { KIAALKEKIAALKEKIAALKEKIAALKEGGGGGKBiotin- } \\
\end{array}$ \\
\hline
\end{tabular}

Table S1. Sequences of all peptides used. Peptide names and corresponding peptide sequences used.

A
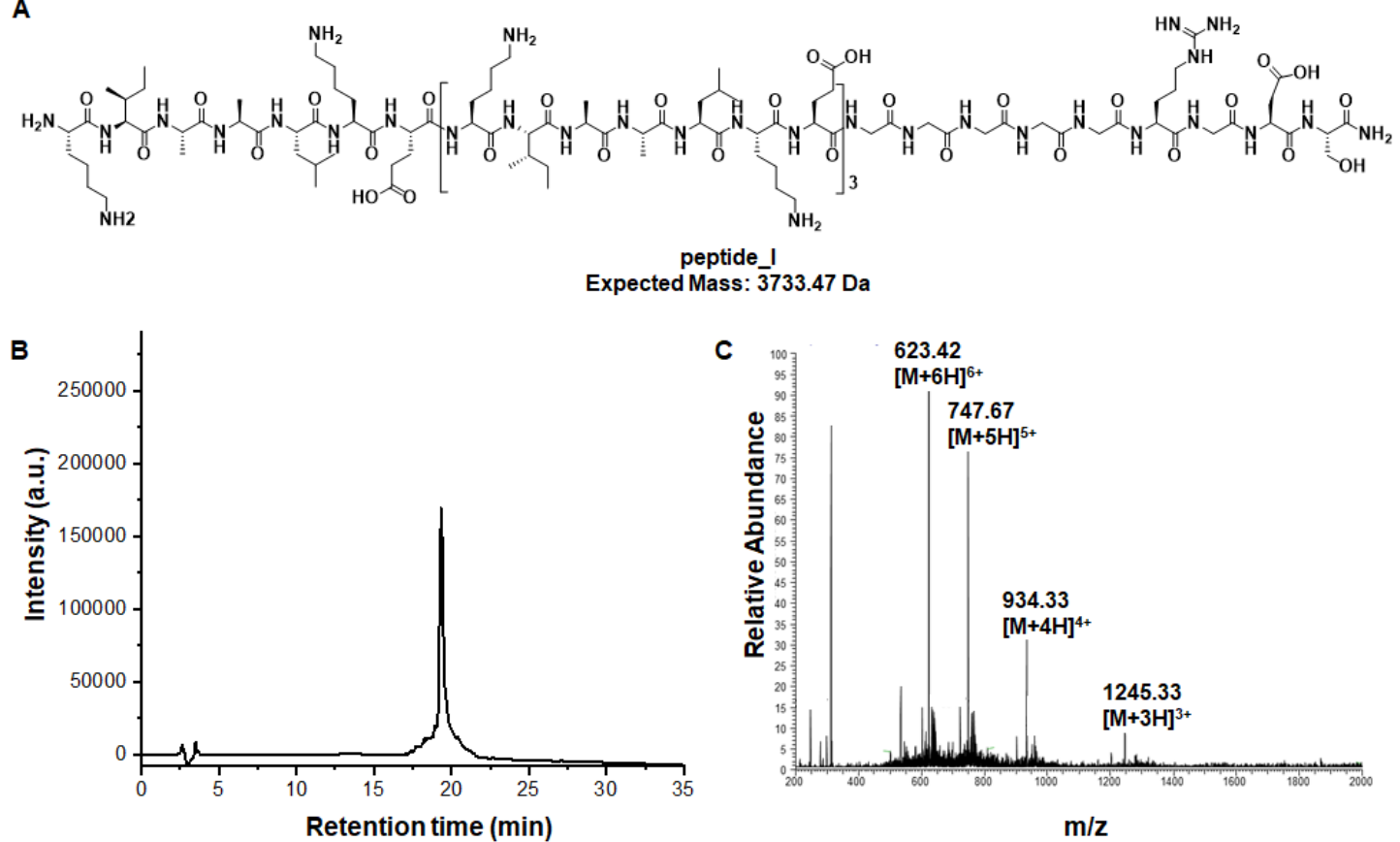

Figure S1. Structure and HPLC-MS characterization of peptide_I. (A) Chemical structure and expected mass of peptide I. (B) Analytical HPLC (monitoring peptide absorbance at $214 \mathrm{~nm}$ ) and (C) ESI-MS confirmed the peptide identity and high purity. 
A
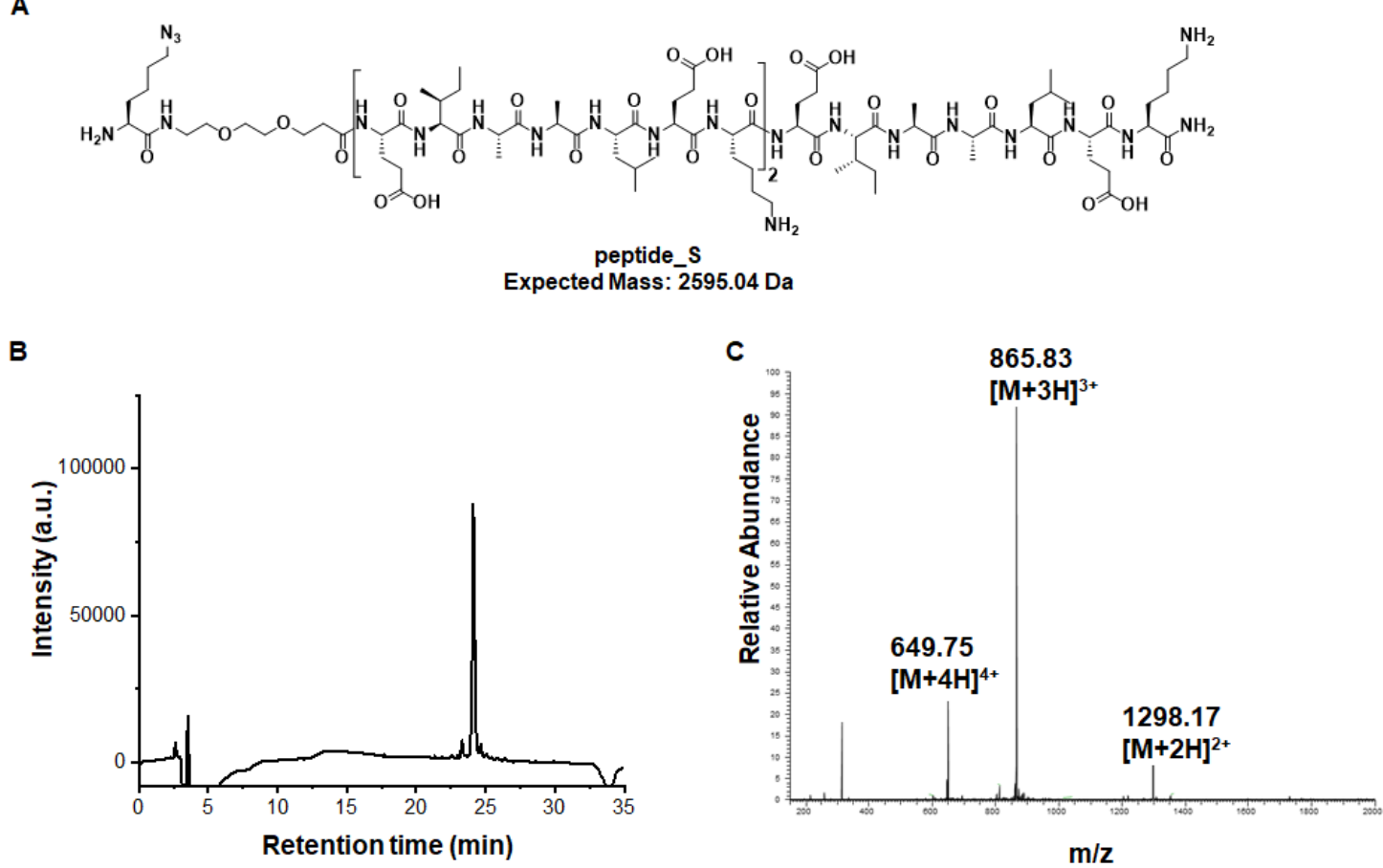

Figure S2. Structure and HPLC-MS characterization of peptide_S. (A) Chemical structure and expected mass of peptide_S (Kaz-PEG2-EIAALEKEIAALEKEIAALEK). (B) Analytical HPLC (monitoring peptide absorbance at $214 \mathrm{~nm}$ ) and (C) ESI-MS confirmed the peptide identity and high purity. 

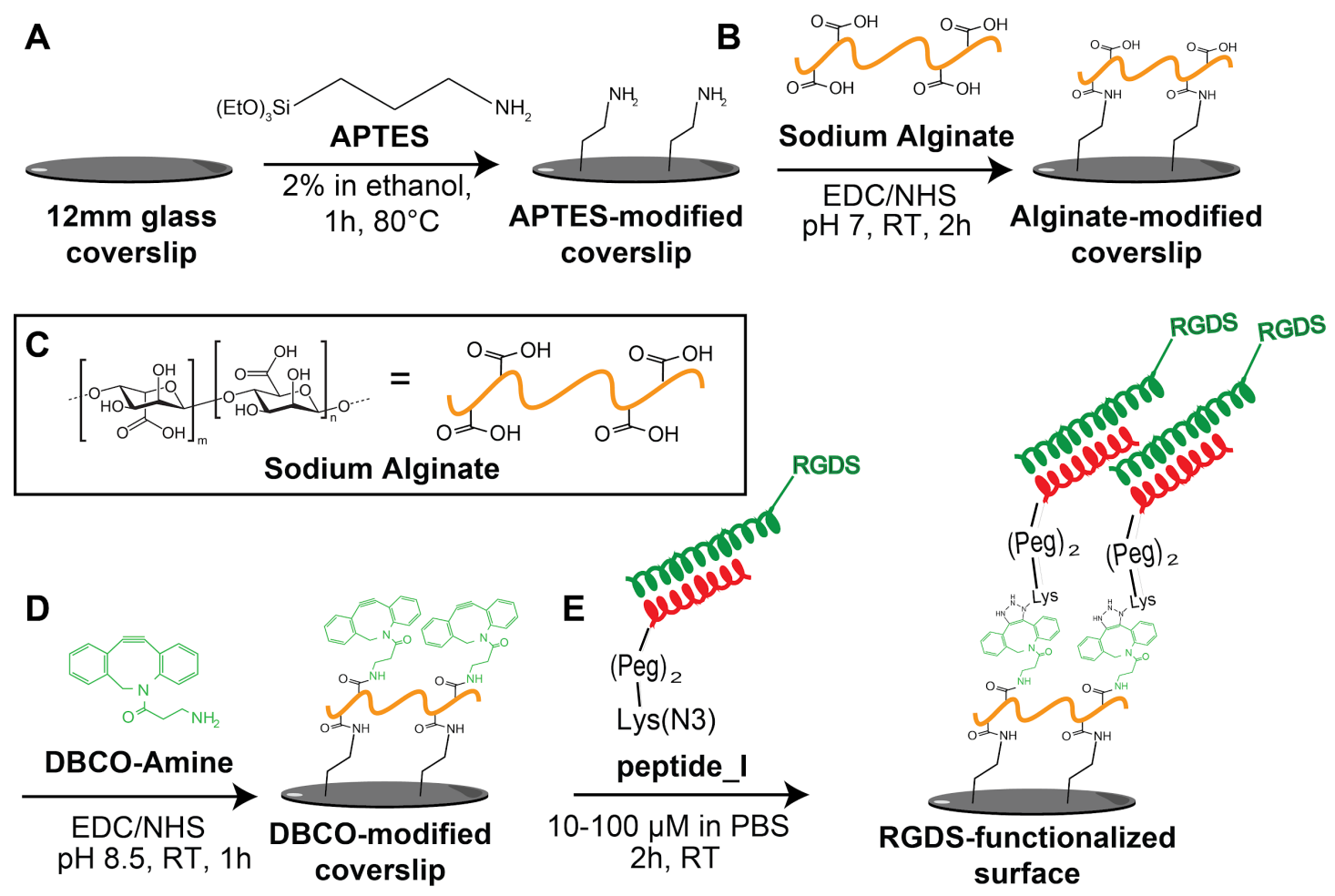

Figure S3. Schematics of surface modification method. (A) Glass coverslips were coated with (3-aminopropyl)triethoxysilane (APTES). (B) APTES surfaces were modified with a layer of sodium alginate $(0.5 \mathrm{wt} \%)$ through an EDC/NHS conjugation.

(C) Chemical formula of sodium alginate. (D) Alginate surface was modified with DBCO-amine through an EDC/NHS reaction (E) peptide_S/peptide_I-RGDS hybrid was added to the DBCO surface using copper-free click chemistry. 
A

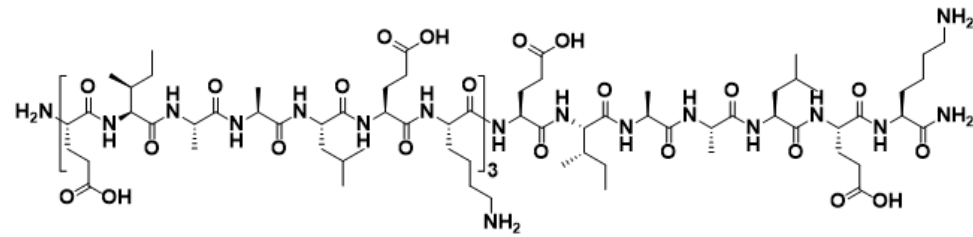

peptide_D

Expected Mass: $3036.56 \mathrm{Da}$

B

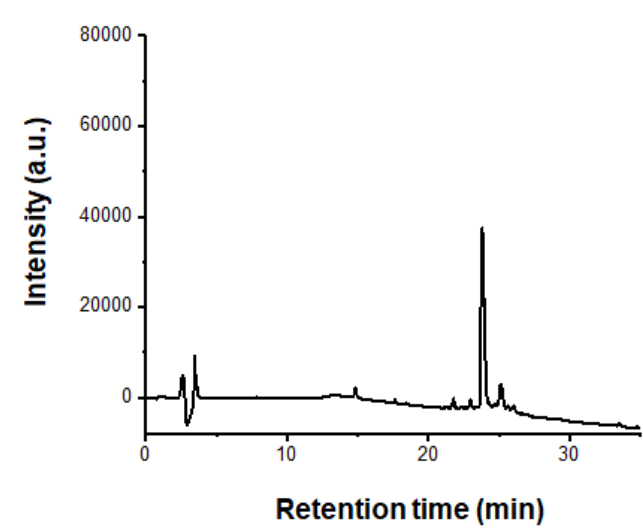

c

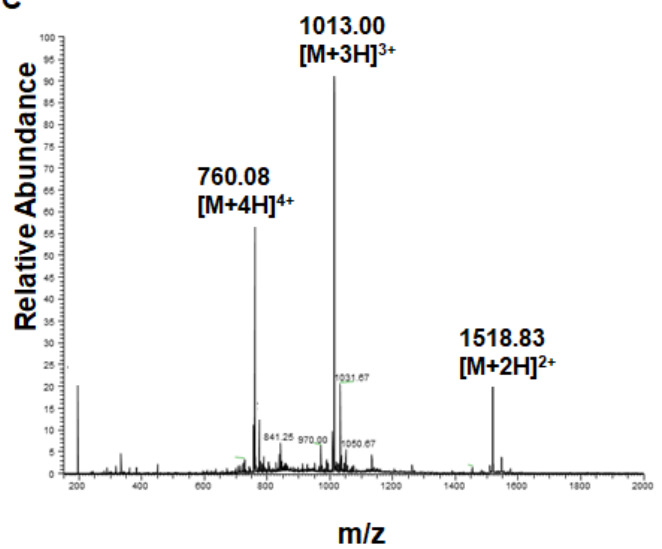

Figure S4. Structure and HPLC-MS characterization of peptide_D. (A) Chemical structure and expected mass of peptide_D (EIAALEKEIAALEKEIAALEKEIAALEK). (B) Analytical HPLC (monitoring peptide absorbance at $214 \mathrm{~nm}$ ) and (C) ESI-MS confirmed the peptide identity and high purity.

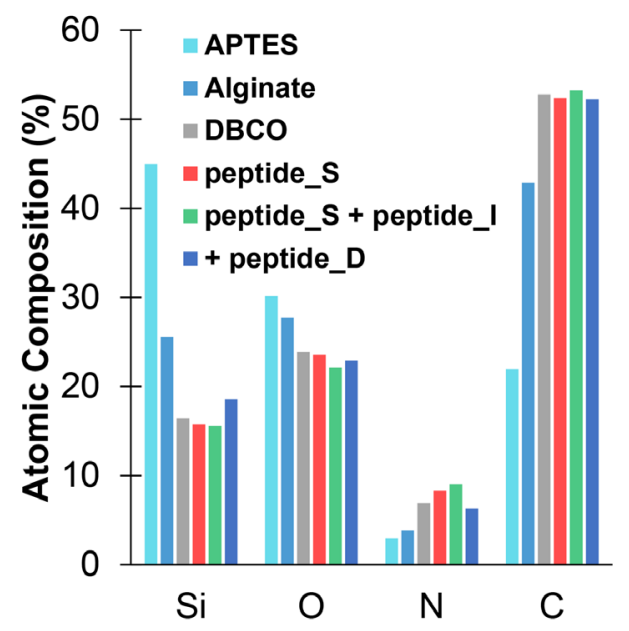

Figure S5. XPS characterization of the atomic composition of the modified surfaces. Percent atomic composition of the surface from XPS data obtained at each layer of chemical modification. Values were used to compute the $\mathrm{C} / \mathrm{O}$ and $\mathrm{C} / \mathrm{N}$ ratios described in Figure 1C. A decrease in percent $\mathrm{Si}$ and $\mathrm{O}$ suggests layering on the glass substrate. A progressive increase in percent $\mathrm{N}$ and $\mathrm{C}$ from APTES to alginate to DBCO to peptide_S suggests successful chemical layering at each step to modify the surface with peptide. 


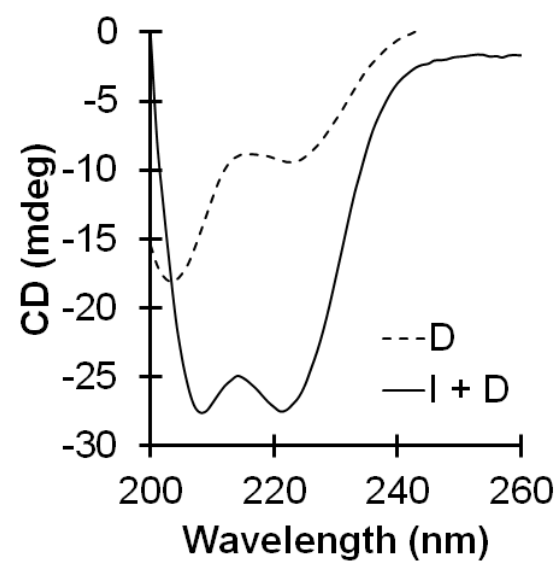

Figure S6. Circular dichroism of peptide_D and peptide_I + peptide_D. The peptide_D spectrum is typical for $\alpha$-helix peptides; the minima at $222 \mathrm{~nm}$ and a larger minima at $208 \mathrm{~nm}$ suggest that the peptide is forming an $\alpha$-helix. The peptide_I + peptide_D spectrum has minima at $222 \mathrm{~nm}$ and $208 \mathrm{~nm}$ that are about equal in intensity, suggesting that the $\alpha$-helices have formed a coiled-coil.

\begin{tabular}{|c|c|}
\hline Peptide(s) & {$[\boldsymbol{\theta}]$ 222 : [0] 208 } \\
\hline$S$ & 0.60 \\
\hline$I$ & 0.80 \\
\hline$D$ & 0.65 \\
\hline$S+I$ & 0.95 \\
\hline$I+D$ & 0.99 \\
\hline$S+I+D$ & 0.91 \\
\hline
\end{tabular}

Table S2. Molar ellipticity ratios of the CD data at $222 \mathrm{~nm}$ to $208 \mathrm{~nm}$. Ellipticity ratios close to or above 1.00 suggest the formation of a coiled-coil. 


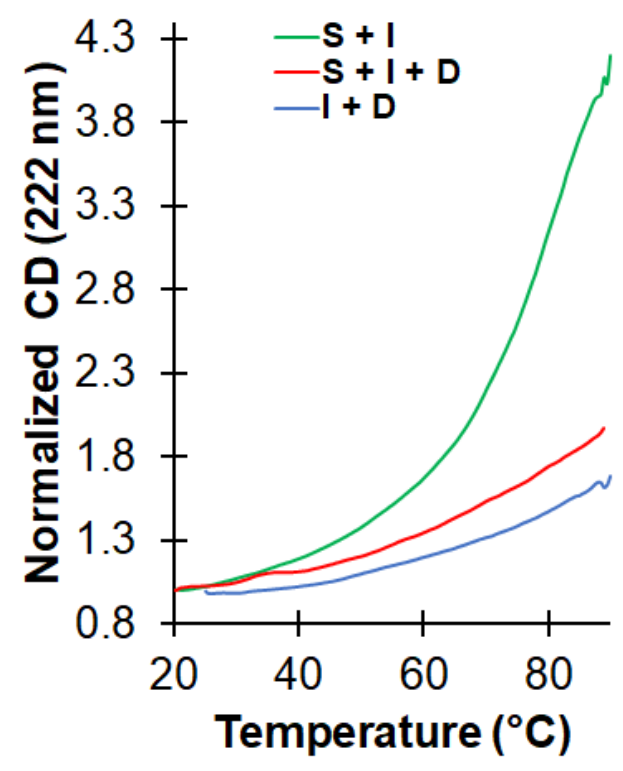

Figure S7. Melting analysis. Melting curves of a mixture of peptide_S + peptide_I (green), peptide_D added to a mixture of peptide_S + peptide_I (red) and a mixture of peptide_I + peptide_D (blue). The CD (in mdeg) at $222 \mathrm{~nm}$ was recorded over a temperature ramp from $25-90^{\circ} \mathrm{C}$ at $1{ }^{\circ} \mathrm{C} / \mathrm{min}$.

A
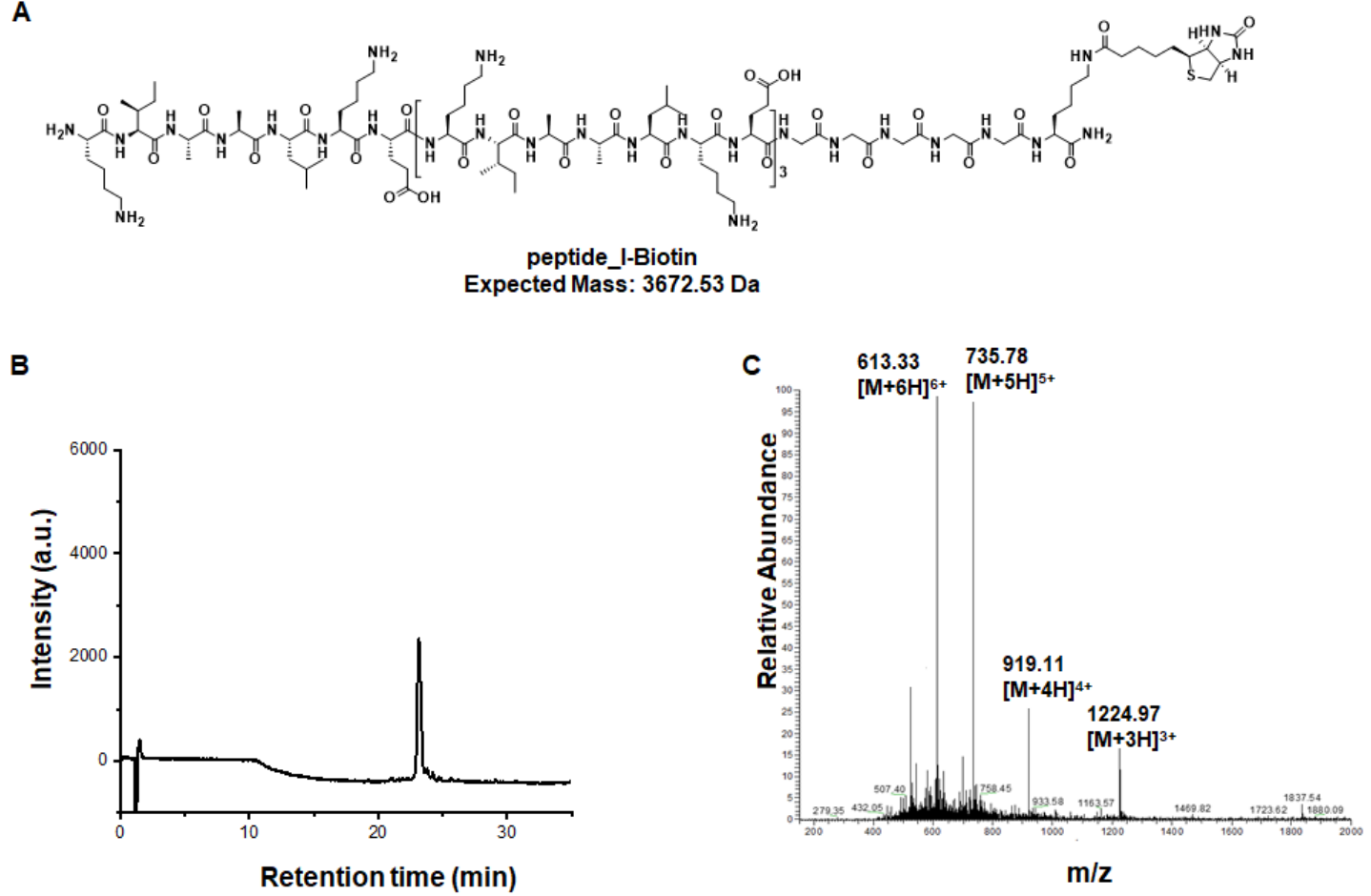

Figure S8. Structure and HPLC-MS characterization of peptide_I-biotin. (A) Chemical structure and expected mass of peptide_Ibiotin (KIAALKEKIAALKEKIAALKEKIAALKEGGGGGK(biotin)). Analytical HPLC (monitoring peptide absorbance at $214 \mathrm{~nm}$ ) and (C) ESI-MS confirmed the peptide identity and high purity. 


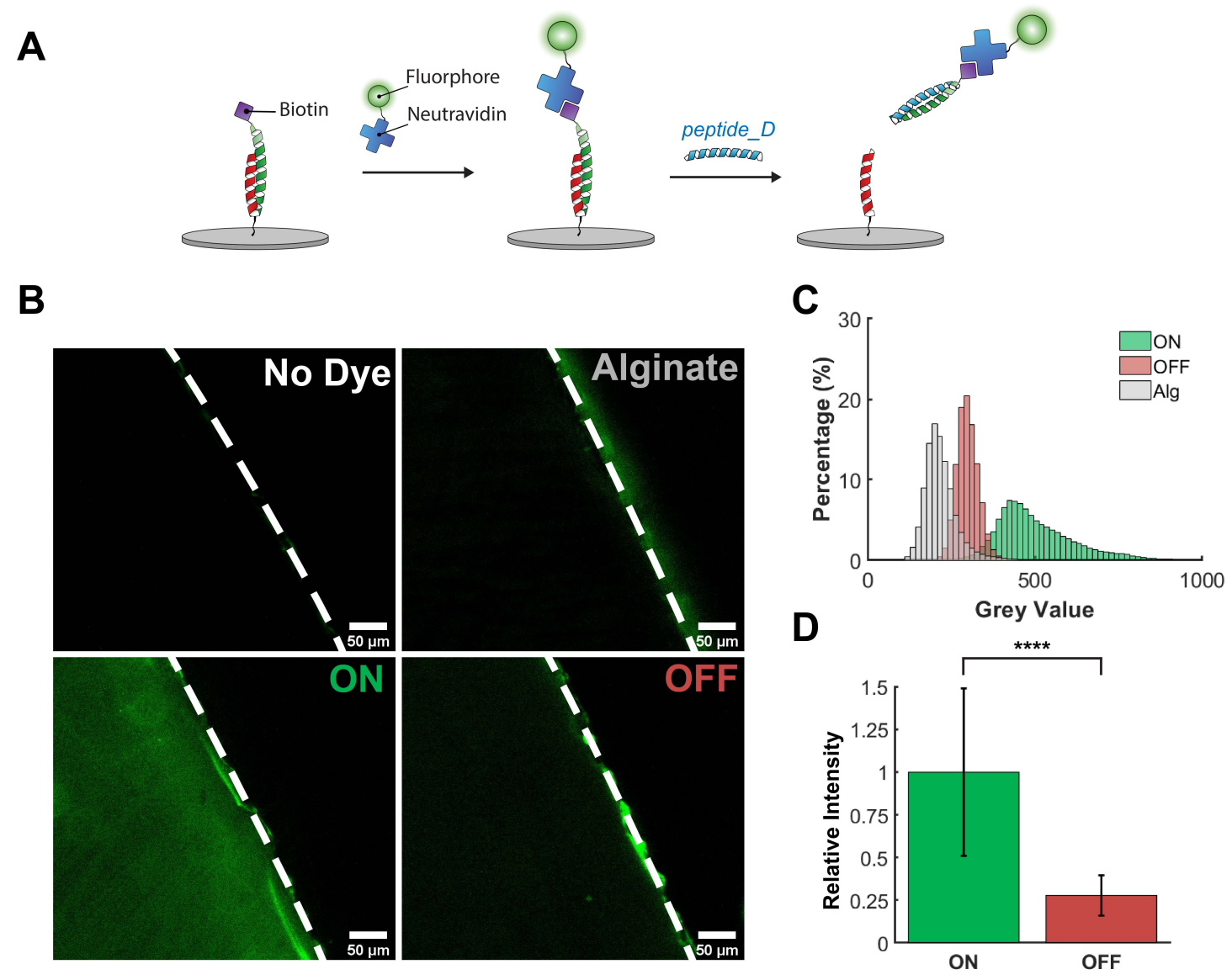

Figure S9. Fluorescent Imaging of Peptide Modification and Displacement. (A) Schematic representation of the fluorescently-labeled and displaced surfaces. (B) Representative images of coverslips with no dye added, Alginate + dye, ON, and OFF. (C) Histogram showing grey values for the coverslips in B (excluding No dye). (D) Fluorescence intensity of the displayed (ON) vs displaced (OFF) surfaces, using the alginate surface to account for non-specific binding. Fluorophore - OregonGreen 488. 
A

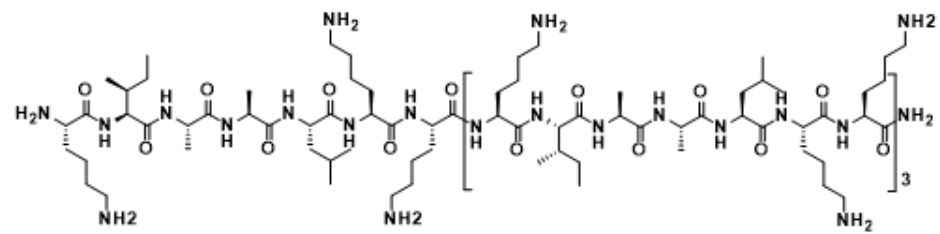

peptide_D-mis

Expected Mass: $3029.04 \mathrm{Da}$

B

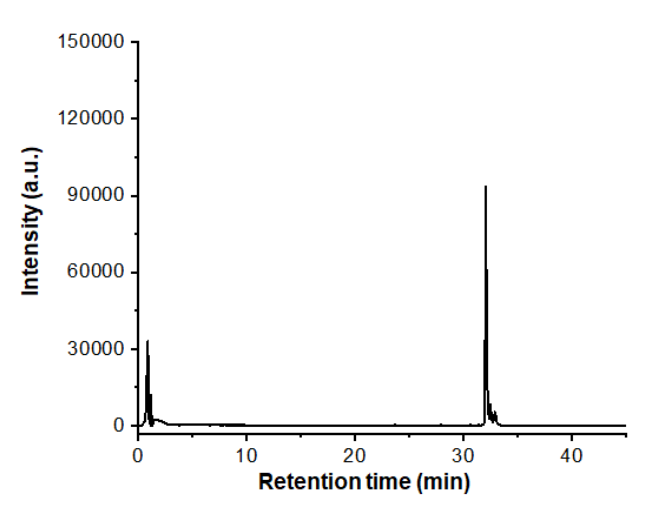

C

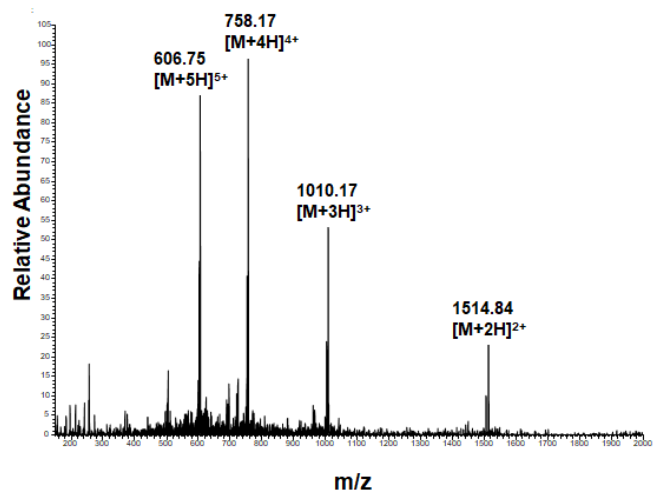

Figure S10. Structure and HPLC-MS characterization of peptide_D-mis. (A) Chemical structure and mass of peptide_D-mis (KIAALKKKIAALKKKIAALKKKIAALKK). (B) Analytical HPLC (monitoring peptide absorbance at $214 \mathrm{~nm}$ ) and (C) ESI-MS confirmed the peptide identity and high purity. 

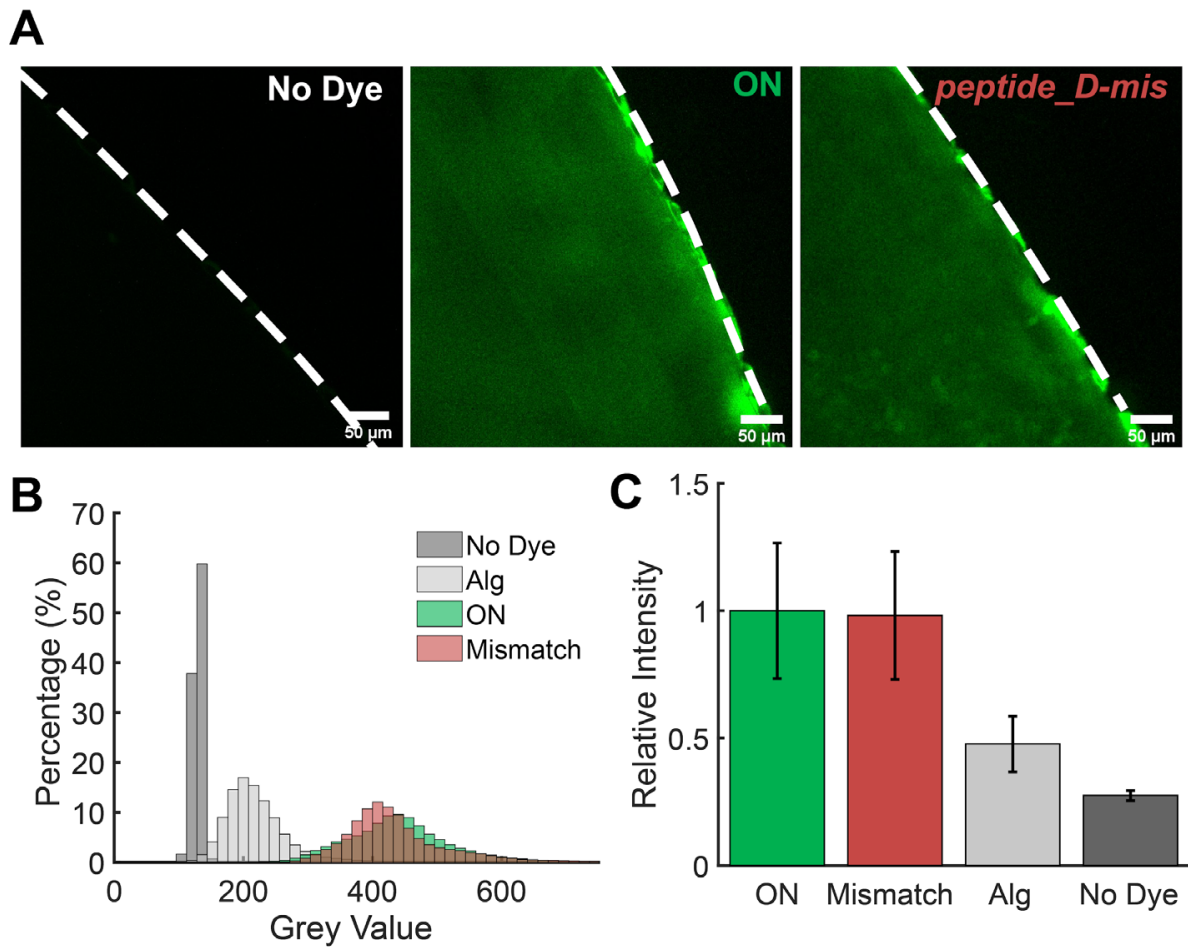

Figure S11. Testing the specificity of the displacement process. (A) Representative images of coverslips with no dye added, ON, and displacement with peptide_D-mis. (B) Histogram showing grey values for the surfaces in A, and alginate surfaces. (D) Relative mean fluorescence intensity of the ON, after adding mismatched displacer, alginate, and no dye surfaces. Fluorophore - OregonGreen 488. 


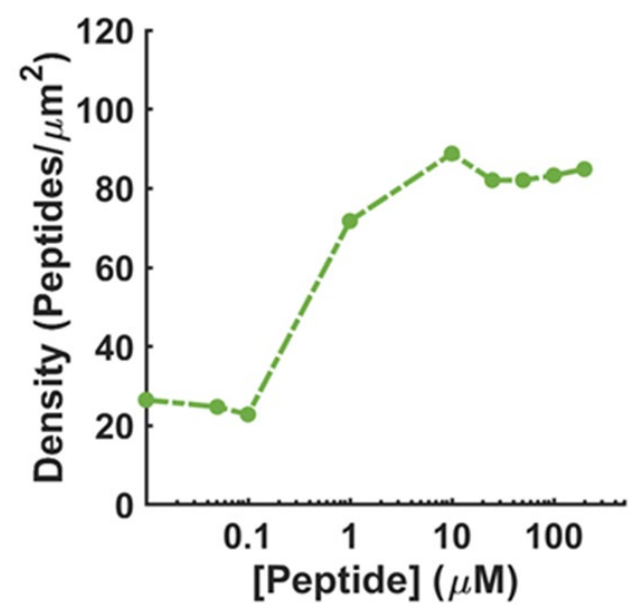

Figure S12. Density of peptides on the surface. Density of peptide_I on the surface as a function of applied peptide concentration, as determined by the HRP assay in Figure 2C.

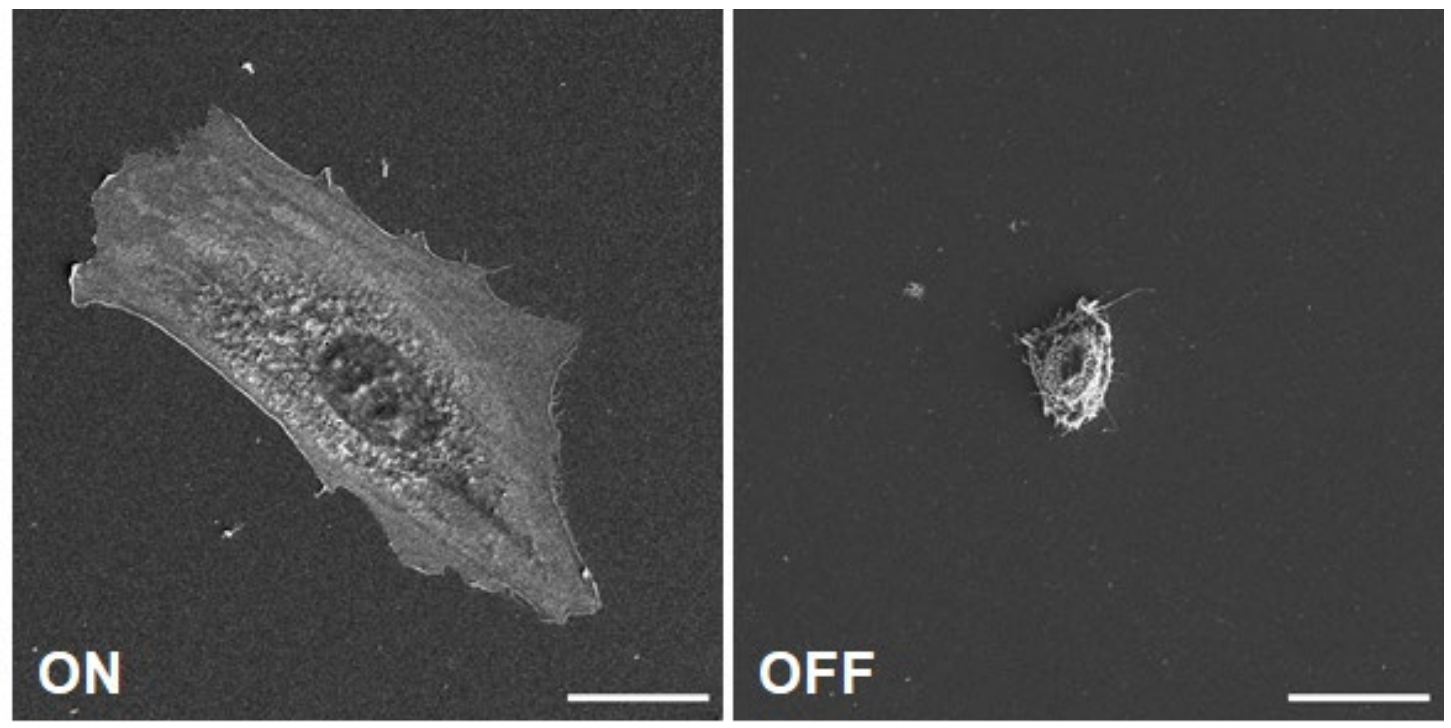

Figure S13. Scanning electron microscopy images of a 3T3 cell cultured on RGDSdisplayed (left) and displaced (right) surfaces (scale bar: $20 \mu \mathrm{m}$ ). 

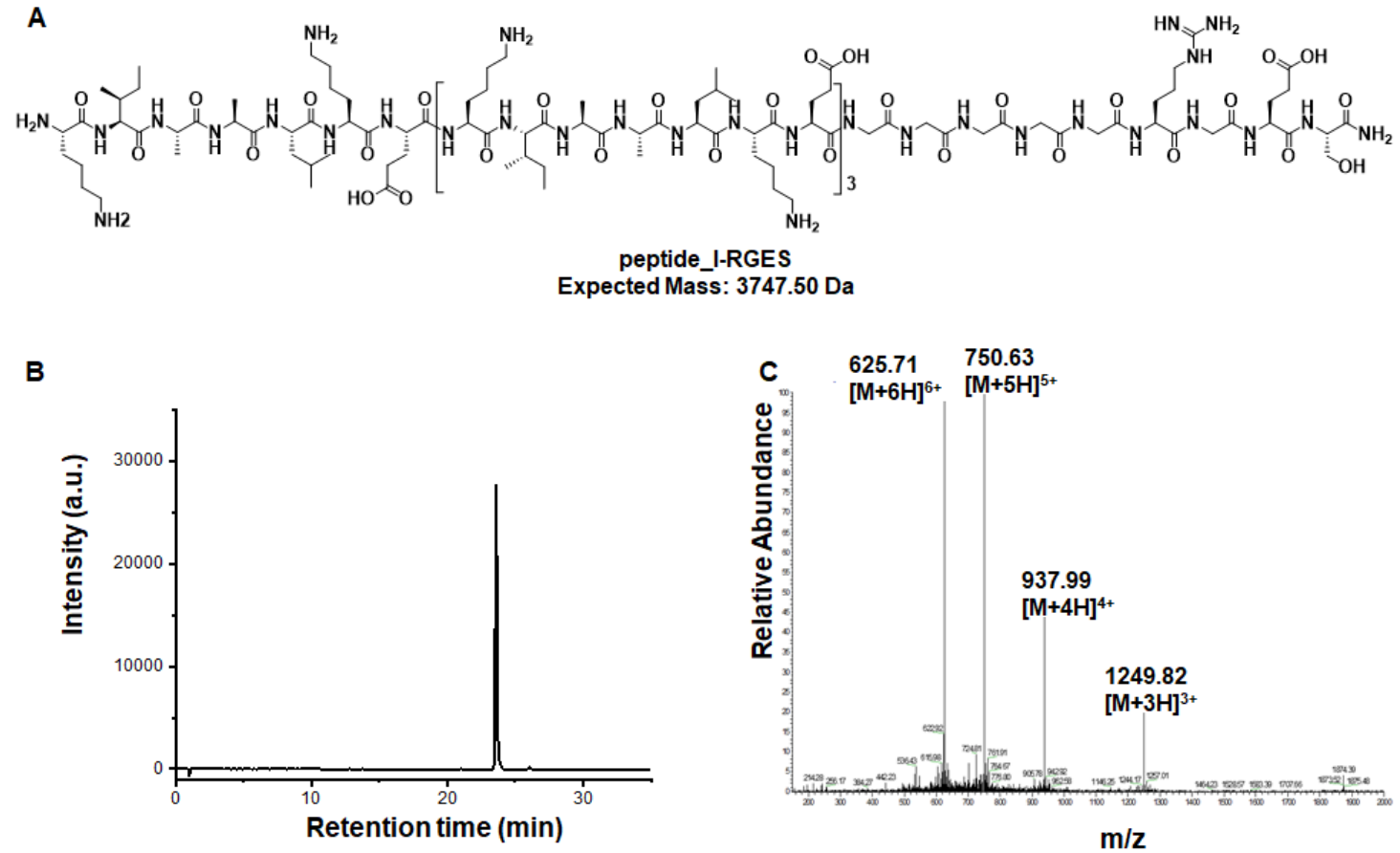

Figure S14. Structure and HPLC-MS characterization of peptide_I-RGES. (A) Chemical structure and expected mass of peptide IRGES (KIAALKEKIAALKEKIAALKEKIAALKEGGGGGRGES). (B) Analytical HPLC (monitoring peptide absorbance at $214 \mathrm{~nm}$ ) and (C) ESI-MS confirmed the peptide identity and high purity.

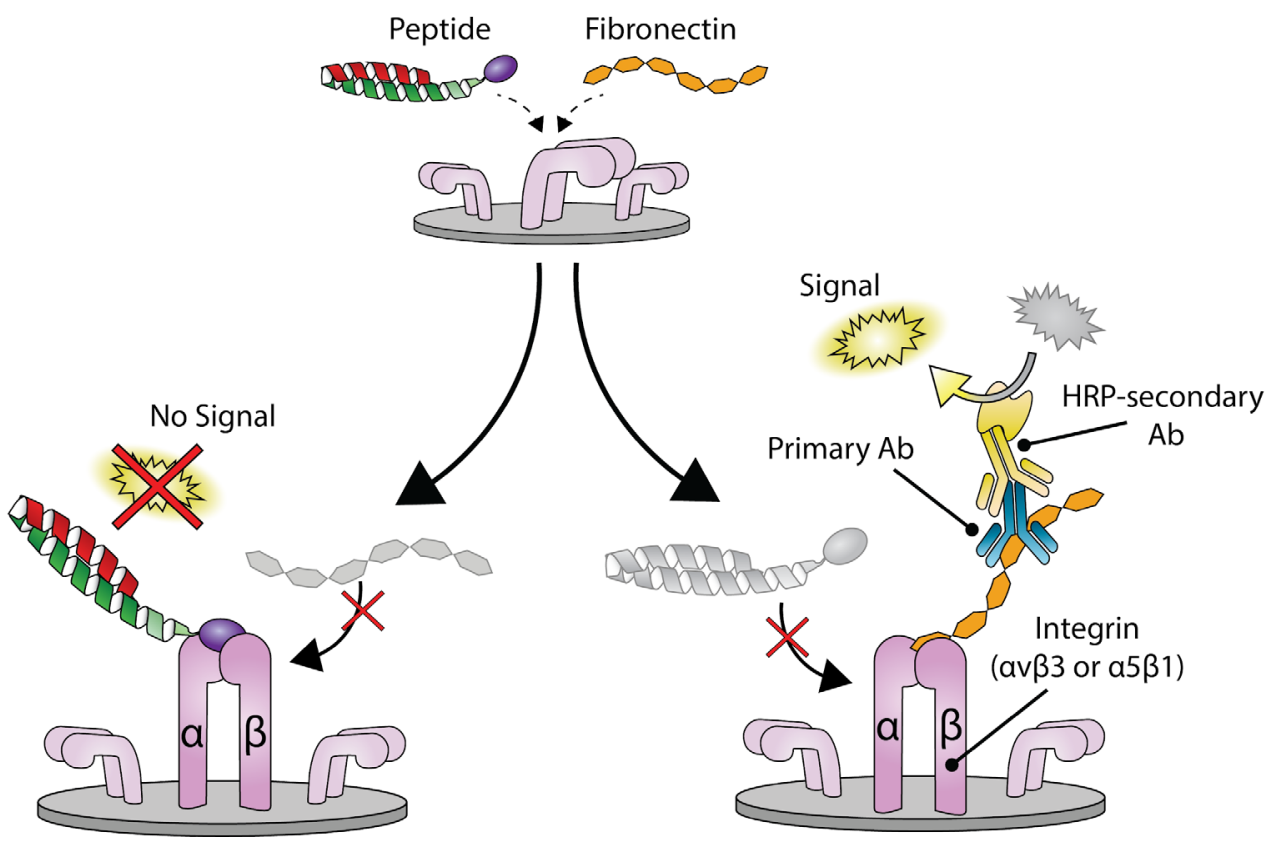

Figure S15. Schematic of the ELISA experiments. Integrin modified plates are incubated with fibronectin and varying concentrations of peptide-I_RDGS. When the peptide inhibits fibronectin binding to the integrins (left), no signal is detected. Without peptide inhibition (right), fibronectin binds the integrins and is then detected using HRP-modified antibodies. 


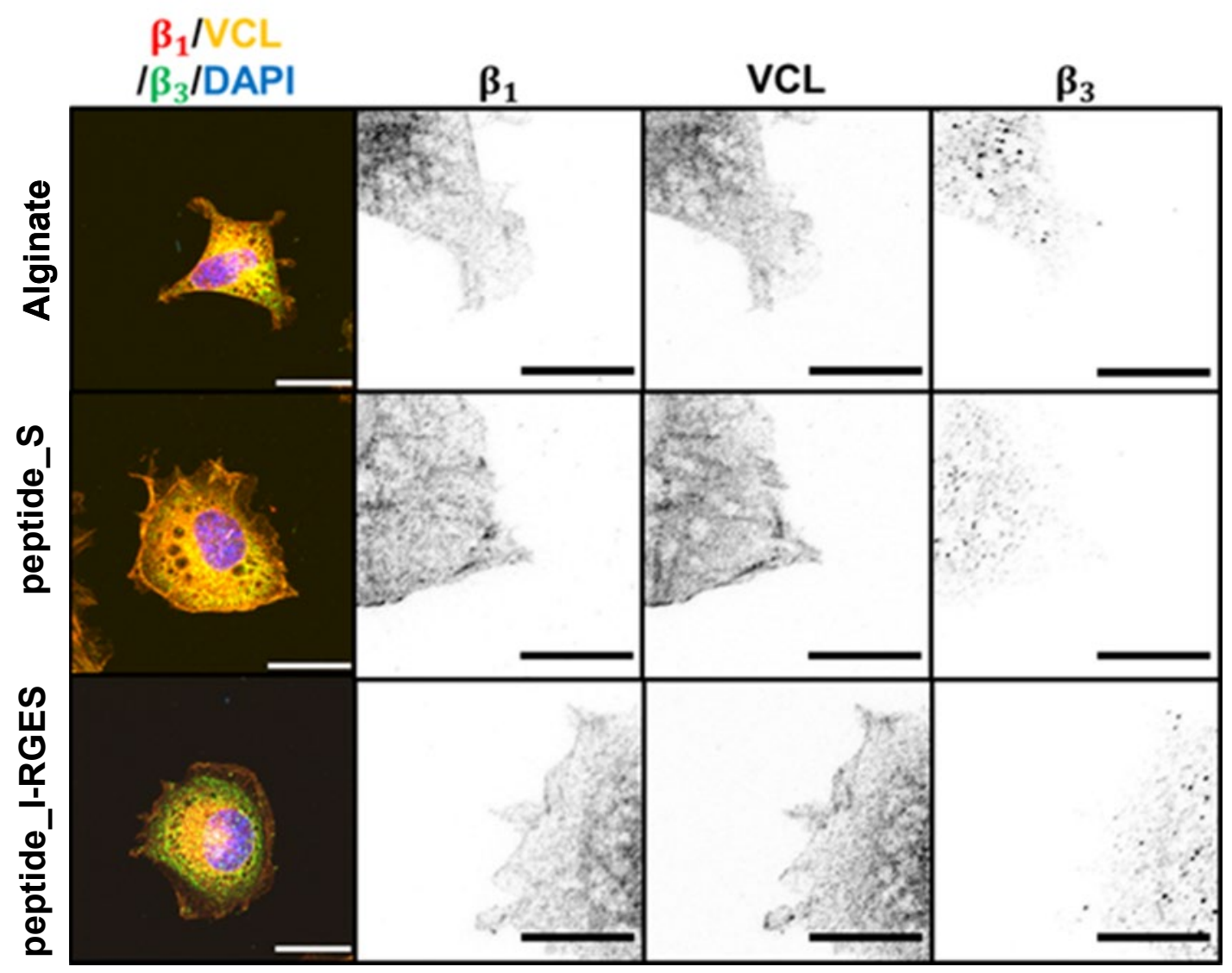

Figure S16. Cell adhesion on control surfaces. Cells cultured on surfaces of Alginate, peptide_S, and peptide_I-RGES did not display significant focal adhesions or $\beta_{1} / \beta_{3}$ colocalization. 


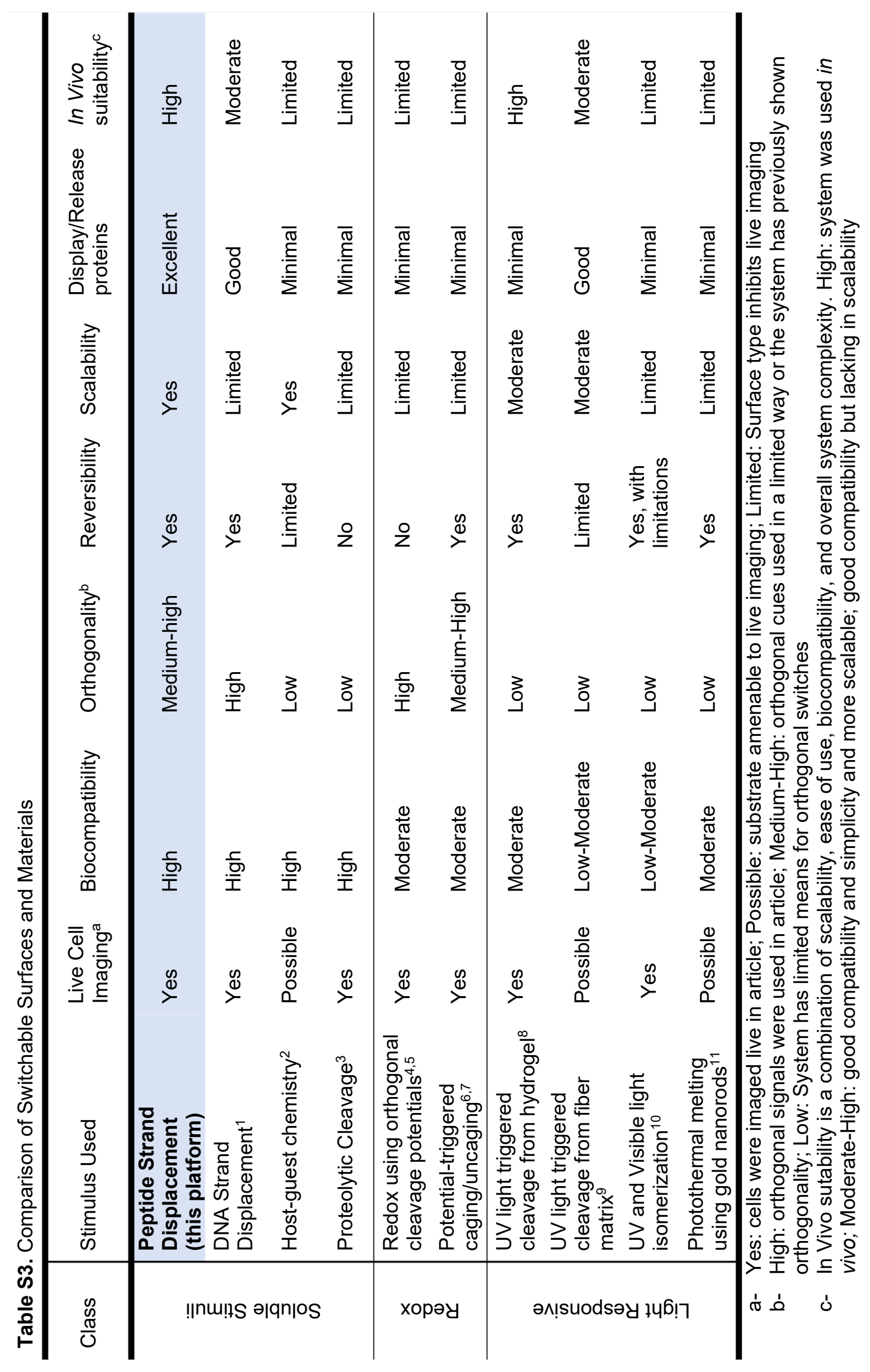




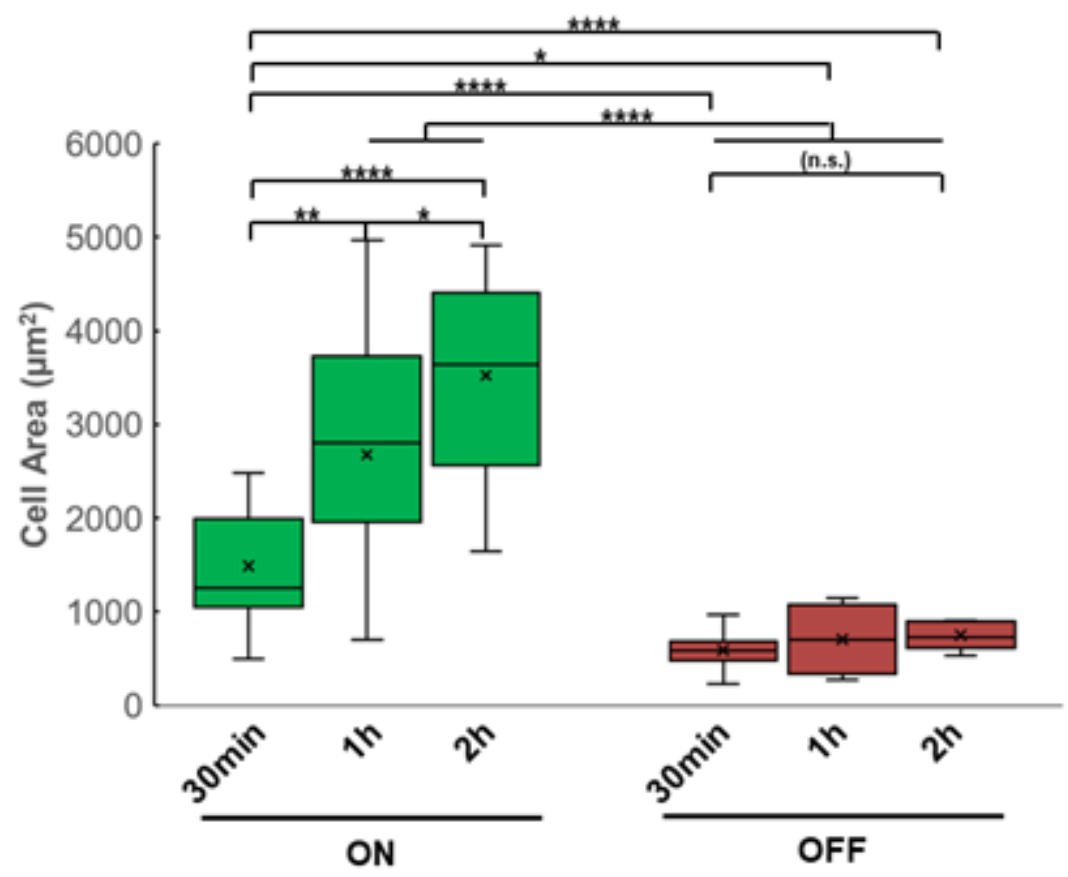

Figure S17. Cell area as a function of signal display time before displacement. PValues: $*<0.05, * *<0.01, * * *<0.001, * * * *<0.0001$.

A
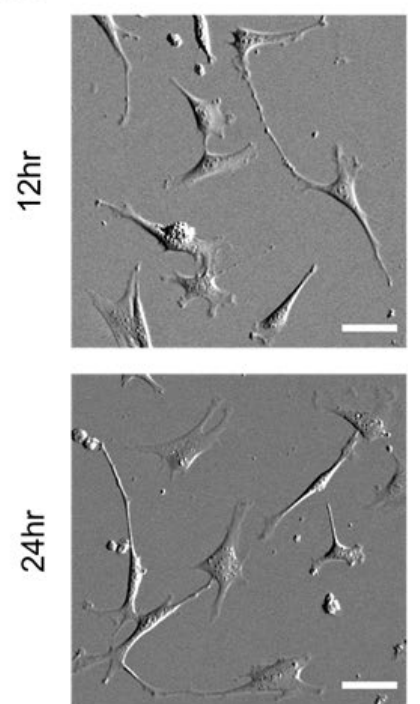

OFF
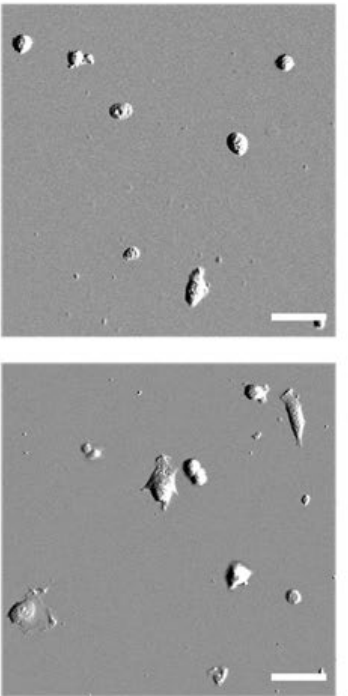

B

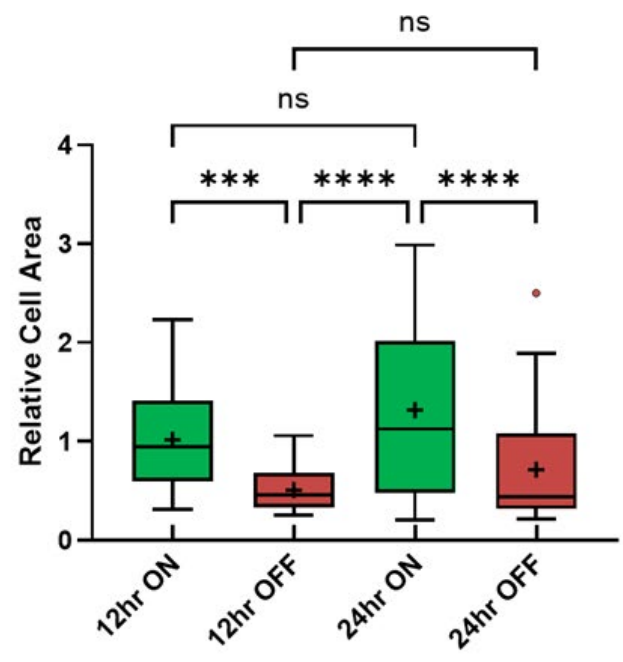

Figure S18. Cell adhesion and displacement on modified Surfaces at extended culture times. A) Representative DIC images of $3 \mathrm{~T} 3$ cells at $12 \mathrm{hr}$ ON and OFF and $24 \mathrm{hr}$ ON and OFF. Scale bar $=50 \mu \mathrm{m}$. B) Average cell area at the respective time points. $\mathrm{N}>30$ cells. 

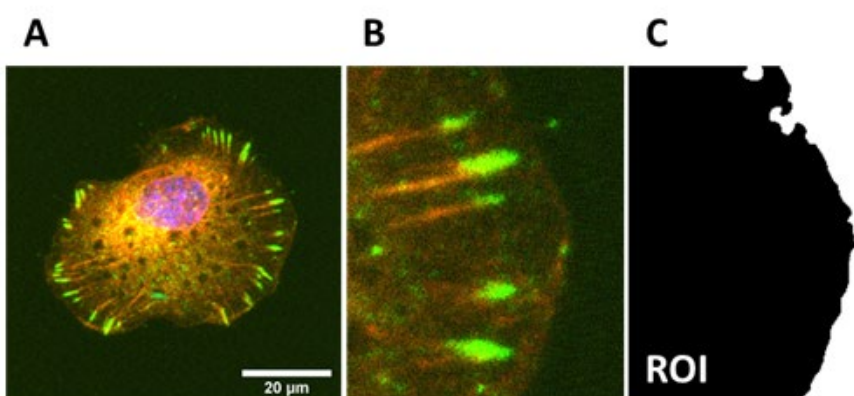

D

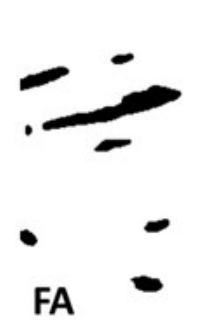

E

$$
\begin{aligned}
& E R_{\beta_{1}}=\frac{I_{F A_{\beta_{1}}}}{I_{R O I} \beta_{1}} \\
& E R_{\beta_{3}}=\frac{I_{F A_{\beta_{3}}}}{I_{R O I \beta_{3}}}
\end{aligned}
$$

Figure S19: Analysis of integrin enrichment ratio. (A) CLSM image of cell and (B) region of interest (ROI) selected. (C) Area of the cell determined automatically and (D) area of the focal adhesions determined automatically through vinculin staining from the region of interest. (E) Measurements and calculation of enrichment ratio. Intensity of focal adhesions was not included in the ROI measurement.

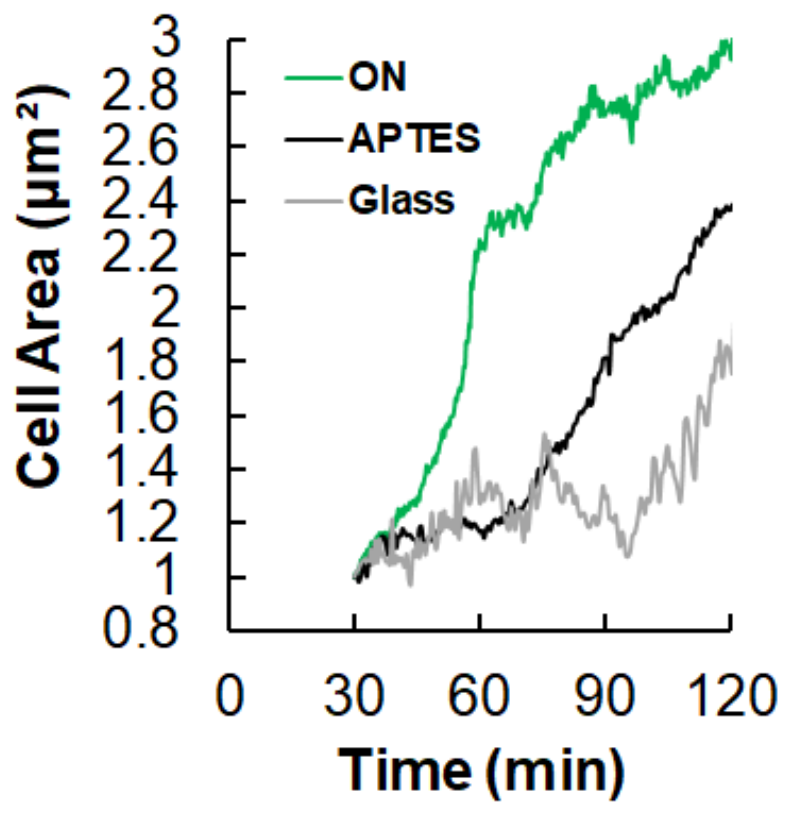

Figure S20. Cell spreading kinetics on surfaces displaying peptide_I compared to controls. Increase in average cell area over time on a surface in the ON state compared to an APTES-coated surface and glass. Kinetic curves of cell spreading were normalized to the initial cell area. 

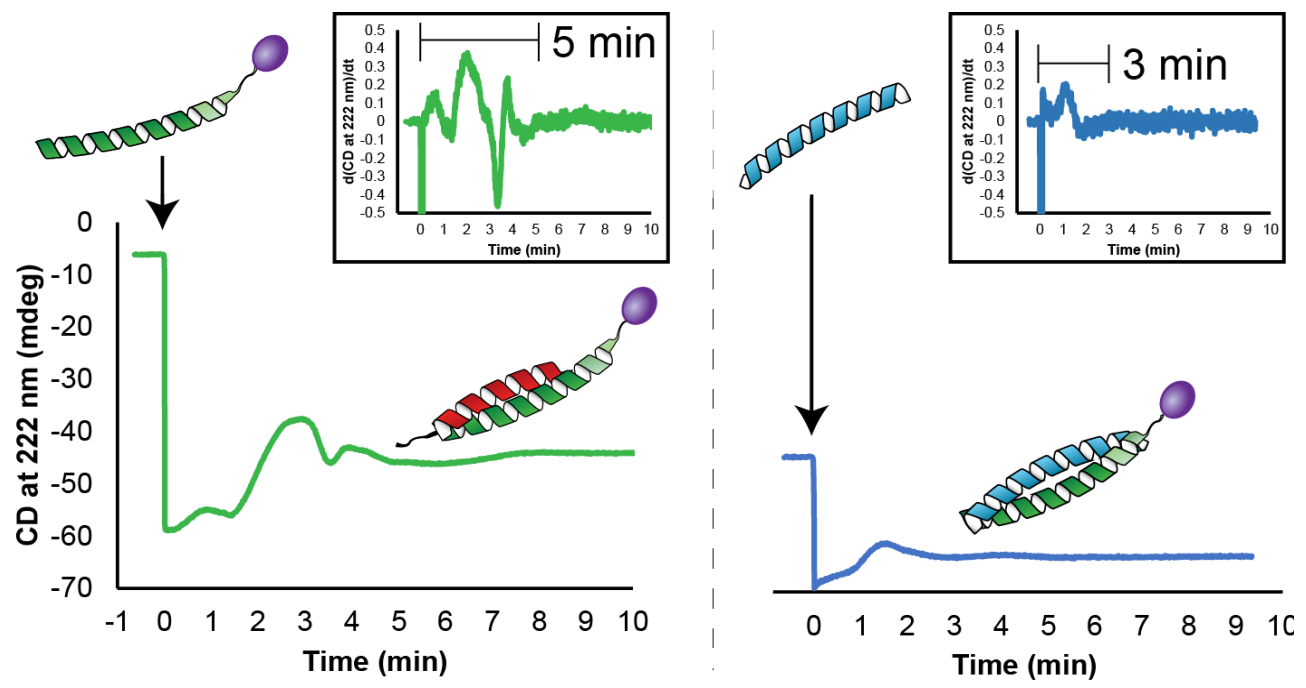

Figure S21. Coiled-coil characteristics of peptide_I addition and displacement. Circular dichroism of peptides in solution, diluted in PBS to $60 \mu \mathrm{M}$ at $37^{\circ} \mathrm{C}$ to mimic cell testing conditions. CD signal at $222 \mathrm{~nm}$ over time of peptide_S with subsequent additions of peptide_I (green) followed by the displacer peptide_D (blue). Insets show the derivative of the CD signal at $222 \mathrm{~nm}$ over time, showing the time it takes to form the peptide_S/peptide_I dimer (green; $5 \mathrm{~min}$ ) and the time it takes to displace peptide_S and form the peptide_I/peptide_D dimer (blue; $3 \mathrm{~min}$ ).

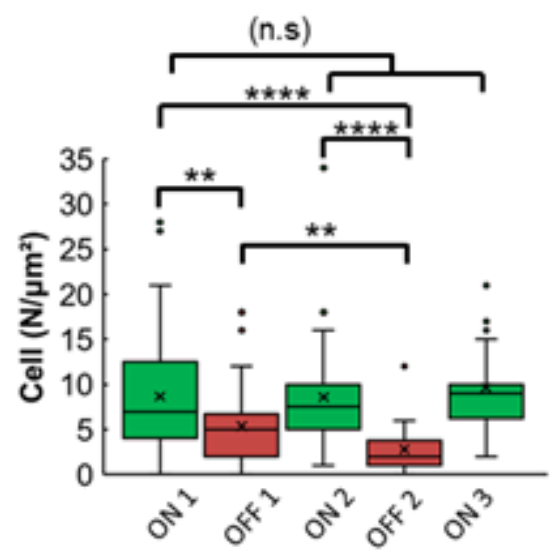

Figure S22. Number of cells per square micron at each cycle step. P-Values: $*<0.05, * *<0.01, * * *<0.001, * * * *<0.0001$. 

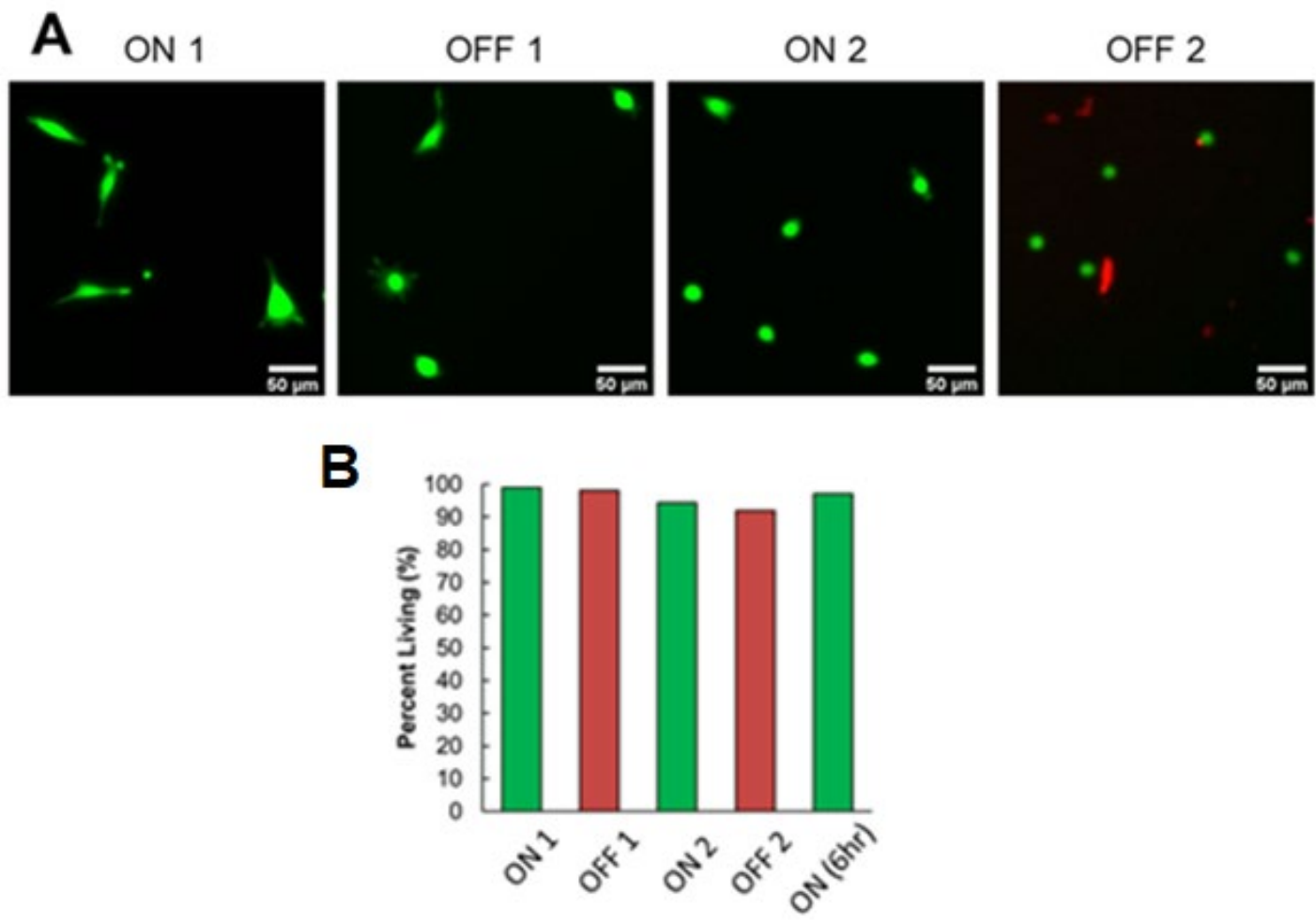

Figure S23. Live-dead assay to determine cell viability. (A) Representative confocal microscopy images. (B) Quantification of cell viability from confocal microscopy shows $>90 \%$ cell viability with all display-displace cycles. 


\section{Supplementary Videos}

Video S1. Video of NIH $3 T 3$ cells spreading on a peptide_I-RGDS surface 20x DIC video of NIH 3 T3 cells plated on fully modified peptide_I-RGDS surface. Time stamp represents time since the video started. Cells were plated 30 minutes prior to the start of the video; images taken every 30 seconds.

Video S2. Video of NIH 3 T3 cells on an alginate surface 10x DIC video of NIH 3 T3 cells plated on a surface modified only with alginate. The non-fouling surface shows little to no spreading without bioactive RGDS signal present. Time stamp represents time since the video started. Cells were plated 30 minutes prior to the start of the video; images taken every minute.

Video S3. Video of NIH $3 T 3$ cells on a surface modified with peptide_S 10x DIC video of NIH 3T3 cells plated on a surface modified only with peptide_S. The negative control surface shows little to no spreading without bioactive RGDS signal present. Time stamp represents time since the video started. Cells were plated 30 minutes prior to the start of the video, images taken every minute.

Video S4. Video of HEK $293 T$ cells on a peptide_I-RGDS surface 10x DIC Video of HEK 293T cells plated on a peptide_I-RGDS modified surface. Cells are significantly less responsive to the RGDS signal due to lack of integrin $\alpha_{5} \beta_{1}$ expression and show little to no adhesion on the surface. Time stamp represents time since the video started. Cells were plated 30 minutes prior to the start of the video; images taken every minute.

Video S5. Video of cells in response to signal display and displacement 10x DIC Video of NIH 3T3 cells plated on a peptide_I-RGDS modified surface. Cells spread and contract with addition of peptide signals (peptide_I-RGDS for "ON" and peptide_D for "OFF"). Timepoints of signal addition and displacement are labeled on the video. Images taken every 15 seconds; time stamp shows time since plating. Scale bar $=100 \mu \mathrm{m}$

Video S6. Video of NIH 3 T3 cells spreading on glass

20x DIC video of NIH 3 T3 cells plated on a bare, plasma-etched glass coverslip (negatively-charged). Time stamp represents time since the video started. Cells were plated 30 minutes prior to the start of the video; images taken every 30 seconds.

Video S7. Video of NIH 3 T3 cells spreading on APTES

20x DIC video of NIH 3T3 cells plated on an APTES coated surface (positivelycharged). Time stamp represents time since the video started. Cells were plated 30 minutes prior to the start of the video; images taken every 30 seconds. 
Table S3 References

(1) Freeman, R.; Stephanopoulos, N.; Álvarez, Z.; Lewis, J. A.; Sur, S.; Serrano, C. M.; Boekhoven, J.; Lee, S. S.; Stupp, S. I. Instructing Cells with Programmable Peptide DNA Hybrids. Nat. Commun. 2017, 8, 15982. https://doi.org/10.1038/ncomms15982.

(2) Boekhoven, J.; Rubert Pérez, C. M.; Sur, S.; Worthy, A.; Stupp, S. I. Dynamic Display of Bioactivity through Host-Guest Chemistry. Angew. Chem. Int. Ed. 2013, 52 (46), 12077-12080. https://doi.org/10.1002/anie.201306278.

(3) Todd, S. J.; Farrar, D.; Gough, J. E.; Ulijn, R. V. Enzyme-Triggered Cell Attachment to Hydrogel Surfaces. Soft Matter 2007, 3 (5), 547. https://doi.org/10.1039/b618256a.

(4) Lee, E.; Luo, W.; Chan, E. W. L.; Yousaf, M. N. A Molecular Smart Surface for Spatio-Temporal Studies of Cell Mobility. PLOS ONE 2015, 10 (6), e0118126. https://doi.org/10.1371/journal.pone.0118126.

(5) Yeo, W.-S.; Mrksich, M. Electroactive Self-Assembled Monolayers That Permit Orthogonal Control over the Adhesion of Cells to Patterned Substrates ${ }^{\dagger}$. Langmuir 2006, 22 (25), 10816-10820. https://doi.org/10.1021/la061212y.

(6) Ng, C. C. A.; Magenau, A.; Ngalim, S. H.; Ciampi, S.; Chockalingham, M.; Harper, J. B.; Gaus, K.; Gooding, J. J. Using an Electrical Potential to Reversibly Switch Surfaces between Two States for Dynamically Controlling Cell Adhesion. Angew. Chem. Int. Ed. 2012, 51 (31), 7706-7710. https://doi.org/10.1002/anie.201202118.

(7) Zhang, L.; Wang, Z.; Das, J.; Labib, M.; Ahmed, S.; Sargent, E. H.; Kelley, S. O. Potential-Responsive Surfaces for Manipulation of Cell Adhesion, Release, and Differentiation. Angew. Chem. Int. Ed Engl. 2019, 58 (41), 14519-14523. https://doi.org/10.1002/anie.201907817.

(8) Lee, T. T.; García, J. R.; Paez, J. I.; Singh, A.; Phelps, E. A.; Weis, S.; Shafiq, Z.; Shekaran, A.; del Campo, A.; García, A. J. Light-Triggered in Vivo Activation of Adhesive Peptides Regulates Cell Adhesion, Inflammation and Vascularization of Biomaterials. Nat. Mater. 2015, 14 (3), 352-360. https://doi.org/10.1038/nmat4157.

(9) Sur, S.; Matson, J. B.; Webber, M. J.; Newcomb, C. J.; Stupp, S. I. Photodynamic Control of Bioactivity in a Nanofiber Matrix. ACS Nano 2012, 6 (12), 10776-10785. https://doi.org/10.1021/nn304101x.

(10) Liu, D.; Xie, Y.; Shao, H.; Jiang, X. Using Azobenzene-Embedded SelfAssembled Monolayers To Photochemically Control Cell Adhesion Reversibly. Angew. Chem. Int. Ed. 2009, 48 (24), 4406-4408. https://doi.org/10.1002/anie.200901130.

(11) Yang, J.; Yao, M.-H.; Du, M.-S.; Jin, R.-M.; Zhao, D.-H.; Ma, J.; Ma, Z.-Y.; Zhao, Y.-D.; Liu, B. A Near-Infrared Light-Controlled System for Reversible Presentation of Bioactive Ligands Using Polypeptide-Engineered Functionalized Gold Nanorods. Chem. Commun. 2015, $51 \quad$ (13), 2569-2572. https://doi.org/10.1039/C4CC09516B. 